\title{
Intensivists in the pediatric intensive care unit: conductors for better operational efficiency
}

\author{
June Dong Park \\ Department of Pediatrics, Seoul National University College of Medicine, Seoul, Korea
}

In this issue of Acute and Critical Care, Kwon et al. [1] from Kyungpook National University Children's Hospital describe the impact of the presence of intensivists in the pediatric intensive care unit (PICU). Their study has several limitations, such as analyzing single-center data from a relatively short period, but they showed that pediatric intensivist staffing in the PICU might improve the operational efficiency of the unit. The authors suggested that the presence of intensivists in the PICU resulted in better occupancy and turnover rates of beds due to more efficient use of the limited resources in the unit. A previous study reported that the presence of intensivists in the PICU resulted in an improved survival rate [2], but Kwon et al. [1] did not show beneficial effects on overall mortality or length of stay in the PICU in their study. I speculate that this discrepancy may result from the fact that their unit is a medical and surgical complex unit, with many potential confounding variables.

The presence of intensivists in the intensive care unit (ICU) is accepted as an inviolable principle in countries with advanced medical systems [3]. As of 2015, there were 12 hospitals in Korea that operated PICUs, and 28 intensivists were working in those units, but there were few units with pediatric intensivists exclusively assigned to the PICU [4]. The previous specialties and subspecialties of those 28 intensivists varied considerably. Most specialized in pediatrics, but they had a diverse range of subspecialties. The most common subspecialty was pulmonology, followed by cardiology. All of them were subspecialty-boarded by the Korean Society of Critical Care Medicine (KSCCM). The roles and responsibilities of intensivists in the ICU may depend on the type of ICU and the characteristics of the hospital. The diversity of the underlying morbidities of patients admitted to the ICU is a major difficulty for intensivists, and the decision-making of intensivists can be influenced by their subspecialty.

Strengthening a trainee's competency as an intensivist primarily depends on the training program during the fellowship course for intensive care medicine, regardless of his or her previous specialty. Therefore, the KSCCM should seriously focus on the training program for fellows from various subspecialties. To increase the proportion of units that have intensivists exclusively assigned to the ICU, all the members of the KSCCM must make our utmost efforts to argue for changes in governmental policies regarding National Health Insurance coverage for intensivists in the ICU.

\section{CONFLICT OF INTEREST}

No potential conflict of interest relevant to this article was reported.

\section{Editorial}

Received: May 26, 2020

Accepted: May 27, 2020

Corresponding author June Dong Park

Department of Pediatrics, Seoul National University College of Medicine, 103 Daehak-ro, Jongno$\mathrm{gu}$, Seoul 03080, Korea

Tel: +82-2-2072-3359

Fax: +82-2-762-3359

E-mail: jdparkmd@snu.ac.kr

Copyright (c) 2020 The Korean Society of Critical Care Medicine

This is an Open Access article distributed under the terms of Creative Attributions Non-Commercial License (https:// creativecommons.org/li-censes/by-nc/4.0/) which permits unrestricted noncommercia use, distribution, and reproduction in any medium, provided the original work is properly cited. 


\section{ORCID}

June Dong Park ～https://orcid.org/0000-0001-8113-1384

\section{REFERENCES}

1. Kwon JE, Roh DE, Kim YH. Effects of the presence of a pediatric intensivist on treatment in the pediatric intensive care unit. Acute Crit Care 2020;35:87-92.

2. Goh AY, Lum LC, Abdel-Latif ME. Impact of 24 hour critical care physician staffing on case-mix adjusted mortality in paediatric intensive care. Lancet 2001;357:445-6.

3. Haupt MT, Bekes CE, Brilli RJ, Carl LC, Gray AW, Jastremski MS, et al. Guidelines on critical care services and personnel: recommendations based on a system of categorization of three levels of care. Crit Care Med 2003;31:2677-83.

4. Yoon JS, Jhang WK, Choi YH, Lee B, Kim YH, Cho HJ, et al. Current status of pediatric critical care in Korea: results of 2015 national survey. J Korean Med Sci 2018;33:e308. 